J. Dairy Sci. 92:720-731

doi:10.3168/jds.2008-1635

(C) American Dairy Science Association, 2009.

\title{
Relative bioavailability of all-rac and RRR vitamin E based on neutrophil function and total $\alpha$-tocopherol and isomer concentrations in periparturient dairy cows and their calves
}

\author{
W. P. Weiss, ${ }^{1}$ J. S. Hogan, and D. J. Wyatt \\ Department of Animal Sciences, Ohio Agricultural Research and Development Center, The Ohio State University, Wooster 44691
}

\begin{abstract}
The objective of this experiment was to determine whether source of supplemental $\alpha$-tocopherol fed to periparturient dairy cows affects neutrophil function and vitamin $\mathrm{E}$ status of the cow and the neonatal calf. Starting $14 \mathrm{~d}$ before anticipated calving and continuing until $14 \mathrm{~d}$ post-parturition, cows were fed diets with no supplemental vitamin $\mathrm{E}$ or with $2,500 \mathrm{IU} / \mathrm{d}$ of vitamin $\mathrm{E}$ from all-rac $\alpha$-tocopheryl acetate or RRR $\alpha$-tocopheryl acetate. All-rac $\alpha$-tocopherol contains equimolar amounts of all 8 stereoisomers, whereas the RRR contains only the RRR isomer. Concentrations of $\alpha$-tocopherol in cow plasma, colostrum, milk, and blood neutrophils were greatest for the RRR treatment, intermediate for all-rac, and lowest for cows fed no supplemental vitamin E. The concentration of $\alpha$-tocopherol in plasma of newborn calves was very low and not affected by treatment but after 6 feedings of their dam's colostrum or milk, concentrations in calf plasma followed the same treatment pattern as cow plasma. The number of bacteria phagocytized was greater by neutrophils from cows fed all-rac vitamin $\mathrm{E}$ than for the other 2 treatments, which resulted in a greater number of bacteria being killed. For cows fed all-rac vitamin $\mathrm{E}$, the $\mathrm{RRR}$ isomer comprised about $20 \%$ of the $\alpha$-tocopherol consumed but approximately $60 \%$ of the $\alpha$-tocopherol in plasma and milk. This enrichment was caused mostly by an almost complete discrimination against the $2 \mathrm{~S}$ isomers. Because all-rac $\alpha$-tocopherol is $50 \% 2 \mathrm{~S}$ isomers, these data suggest that $1 \mathrm{~g}$ of all-rac tocopheryl acetate is equivalent to $0.5 \mathrm{~g}$ of RRR tocopheryl acetate.
\end{abstract}

Key words: vitamin E, stereoisomer, dairy cow, neutrophil

Received August 15, 2008.

Accepted October 21, 2008.

${ }^{1}$ Corresponding author: weiss.6@osu.edu
INTRODUCTION

$\alpha$-Tocopherol has 3 chiral centers such that 8 different stereoisomers can exist. Plants only synthesize the RRR isomer but when $\alpha$-tocopherol is synthesized chemically, all 8 isomers are produced in equimolar concentrations (i.e., all-rac form). The acetate ester of all-rac $\alpha$-tocopherol (all-rac $\alpha$-tocopheryl acetate) is the most common form of supplemental vitamin $\mathrm{E}$ fed to dairy cows because of its cost and stability, and numerous studies have shown that proper supplementation of the all-rac form is beneficial (Smith et al., 1997). The RRR isomer of $\alpha$-tocopherol has greater biopotency than the all-rac form on a molar or mass basis; therefore, the system of defining vitamin E requirements in international units (IU) was developed. Based on the rat fetal resorption assay (Harris and Ludwig, 1949), the US Pharmacopeia (USP) defined 1 $\mathrm{g}$ of all-rac $\alpha$-tocopheryl acetate as equal to $1 \mathrm{IU}$ of vitamin $\mathrm{E}$ and $1 \mathrm{~g}$ of RRR $\alpha$-tocopheryl acetate as equal to $1.36 \mathrm{IU}$ of vitamin $\mathrm{E}$ (all-rac and RRR $\alpha$-tocopherol have 1.10 and $1.49 \mathrm{IU} / \mathrm{g}$, respectively). Several problems have been identified regarding the conversion factors equating different forms of vitamin $\mathrm{E}$ (Blatt et al., 2004). One major concern is that when animals, including cattle, are fed diets that are equal in vitamin $\mathrm{E}$ on an IU basis, concentrations of $\alpha$-tocopherol in biological fluids and tissues are almost always greater when RRR $\alpha$-tocopherol is fed than when all-rac is fed (Lauridsen et al., 2002; Cortinas et al., 2004; Jensen et al., 2006; Meglia et al., 2006). Plasma concentrations of $\alpha$-tocopherol have been related to prevalence of retained fetal membranes and mastitis and neutrophil function (Weiss et al., 1994; LeBlanc et al., 2004). The greater plasma concentrations of $\alpha$-tocopherol obtained when RRR $\alpha$-tocopherol is fed suggests that the IU system may not accurately valuate the different forms of vitamin E.

We hypothesized that supplemental RRR $\alpha$-tocopheryl acetate will increase concentrations of $\alpha$-tocopherol in plasma and neutrophils to a greater extent than will supplemental all-rac $\alpha$-tocopheryl acetate and the resulting improved vitamin E status will enhance 
neutrophil function. In addition we hypothesized that feeding RRR $\alpha$-tocopherol to late gestation cows will increase the concentration of $\alpha$-tocopherol in colostrum and milk and when fed to newborn calves will result in improved vitamin E status of the calf. The objectives of this experiment were to determine whether source of supplemental $\alpha$-tocopherol (RRR or all-rac) fed to periparturient dairy cows affects the concentrations of $\alpha$-tocopherol in plasma, milk, and blood neutrophils, affects the vitamin $\mathrm{E}$ status of the neonatal calf, and affects neutrophil function. The concentrations of specific $\alpha$-tocopherol isomers in plasma and milk were quantified to provide information on why concentrations of total $\alpha$-tocopherol differ and to assist in the development of more appropriate equivalency factors for different forms of vitamin E.

\section{MATERIALS AND METHODS}

\section{Cows and Diets}

All procedures involving animals were approved by The Ohio State University Agricultural Animal Care Committee. At $60 \mathrm{~d}$ before anticipated calving, Holstein cows $(n=18)$ and heifers $(n=18)$ were moved to a single free-stall pen and fed a diet consisting of (DM basis) $15 \%$ corn silage, $24 \%$ grass silage, $44 \%$ grass hay, and $16 \%$ concentrate (approximately $70 \%$ corn grain, 20\% soybean meal, and 10\% mineral and vitamin premix) and was formulated to provide 1,000 IU of supplemental vitamin $\mathrm{E} / \mathrm{d}$ (all-rac $\alpha$-tocopheryl acetate). Cows were blocked (12 blocks) by parity (heifers or cows) and calving date and moved to individual box stalls $14 \mathrm{~d}$ before anticipated parturition and then treatments were initiated. Treatments were: no supplemental vitamin E (control) or 2,500 IU/d of supplemental vitamin $\mathrm{E}$ from either all-rac $\alpha$-tocopheryl acetate (all-rac) or RRR- $\alpha$ tocopheryl acetate (RRR; Natural Source Vitamin E, ADM Animal Nutrition and Health, Quincy, IL). The standard USP factor was used so that cows consumed 2,275 or $1,678 \mathrm{mg} / \mathrm{d}$ of supplemental $\alpha$-tocopherol, respectively, when fed all-rac or RRR supplements. All cows were fed a common prefresh diet (Table 1) ad libitum plus the appropriate treatment premix. Each morning, cows were fed the silage and concentrate portion of their ration and $0.3 \mathrm{~kg}$ (as-fed) of either $100 \%$ ground corn (control) or a mix of ground corn and the appropriate vitamin E source. After the silage and concentrate was mostly consumed, grass hay was fed. Feed refusal (almost exclusively hay) was removed and weighed each morning. After calving cows remained in box stalls for $3 \mathrm{~d}$, then moved to tie stalls and were fed the same $0.3 \mathrm{~kg}$ of premix with a lactation TMR (Table 1) until 15 DIM. Cows were fed every morning and
Table 1. Composition of diets fed before (Prefresh) and after parturition (\% of DM)

\begin{tabular}{lcc}
\hline Item & Prefresh & Lactation \\
\hline Corn silage & 22.60 & 30.0 \\
Alfalfa silage & 22.60 & 25.0 \\
Grass hay, early head & 19.90 & - \\
Ground corn & 19.25 & 16.57 \\
Soybean meal, 44\% CP & 5.78 & 10.34 \\
Soy Pass ${ }^{1}$ & - & 3.25 \\
Roasted soybeans, whole & - & 5.00 \\
Soybean hulls & 9.00 & 7.94 \\
Prefresh mineral vitamin mix $^{2}$ & 0.87 & - \\
Lactation mineral vitamin mix $^{3}$ & - & 1.90 \\
CP, \% & 14.2 & 17.4 \\
NDF, \% & 42.2 & 34.7 \\
Ca, \% & 0.63 & 0.89 \\
P, \% & 0.28 & 0.37 \\
Mg, \% & 0.32 & 0.31 \\
Cu, mg/kg & 16 & 15 \\
Fe, mg/kg & 216 & 286 \\
Zn, mg/kg & 54 & 61 \\
\hline
\end{tabular}

${ }^{1}$ LignoTech USA Inc. (Rothschild, WI).

${ }^{2}$ Contained $29.2 \% \mathrm{CaCO}_{3}, 19.4 \% \mathrm{MgO}, 29.2 \%$ trace mineralized salt, and $11.7 \% \mathrm{Na}_{2} \mathrm{SeO}_{4}$ premix (200 mg of $\mathrm{Se} / \mathrm{kg}$ ), $1.0 \% \mathrm{ZnSO}_{4}, 0.4 \%$ $\mathrm{CuSO}_{4}$, and $9.2 \%$ vitamin premix (provided 6,670 and 1,770 IU of supplemental vitamin $\mathrm{A}$ and $\mathrm{D} / \mathrm{kg}$ of diet DM.

${ }^{3}$ Contained $30.2 \% \mathrm{CaCO}_{3}, 15.6 \%$ dicalcium phosphate, $7.2 \% \mathrm{MgO}$, $37.4 \%$ trace mineralized salt, and $5.6 \% \mathrm{Na}_{2} \mathrm{SeO}_{4}$ premix $(200 \mathrm{mg}$ of $\mathrm{Se} / \mathrm{kg}$ ), $0.3 \% \mathrm{ZnSO}_{4}, 0.1 \% \mathrm{CuSO}_{4}$, and $3.6 \%$ vitamin premix (provided 5,380 and 1,490 IU of supplemental vitamin $\mathrm{A}$ and $\mathrm{D} / \mathrm{kg}$ of diet DM.

premix was added to the top of the TMR. The amount of TMR offered was adjusted to allow for about $10 \%$ feed refusal but because the premix was mixed into the top layer of the TMR and it only comprised about $1 \%$ of the as-fed ration, cows probably consumed most of the premix. Prefresh and lactation diets were supplemented with $0.3 \mathrm{mg} / \mathrm{kg}$ of Se from sodium selenate. Cows were milked twice daily and milk weights were recorded. Cows were weighed when they were moved to the box stalls and at 3 and 14 DIM.

Blood was sampled into heparinized tubes from the tail vein when cows were moved to the box stalls (before treatments started), every Monday, Wednesday, and Friday starting $5 \mathrm{~d}$ before anticipated calving, and 3 and $14 \mathrm{~d}$ postcalving. After cows calved, the blood sample closest to $2 \mathrm{~d}$ before actual calving was used for analyses. Blood samples are designated as $-14 \mathrm{~d}$ (actual day was $-14.8 \pm 4 \mathrm{~d}$ before calving), $-2 \mathrm{~d}$, $3 \mathrm{~d}$, and $14 \mathrm{~d}$. Blood was centrifuged and the plasma was frozen $\left(-20^{\circ} \mathrm{C}\right)$. Neutrophils were isolated from blood sampled on d 3, suspended in Hanks' balanced salt buffer, and the cells were counted (Hogan et al., 1992). A portion of the suspension was used for the function assays (see below) and another portion containing approximately $80 \times 10^{6}$ cells was made to be $1 \%$ pyrogallic acid by adding an appropriate amount of $10 \%$ pyrogallic acid and the solution was frozen until analyzed for $\alpha$-tocopherol. First-milking colostrum, 
transition milk (composited sample of second to sixth milking), and milk (a.m. and p.m. at 14 DIM) samples were stored in the freezer. Feeds were sampled weekly and stored in the freezer.

When a newborn calf was first observed, a blood sample was taken from the jugular vein, the dam was milked, and the calf was fed $3.9 \mathrm{~L}$ of first milking colostrum (for a few calves, an esophageal feeder was used to achieve the target intake). The remaining colostrum was stored in the refrigerator $\left(4^{\circ} \mathrm{C}\right)$. Approximately 12 $\mathrm{h}$ after the first feeding, colostrum was removed from the refrigerator, warmed to $37^{\circ} \mathrm{C}$, and an additional 1.9 $\mathrm{L}$ was fed. For the next $2 \mathrm{~d}$, the dam was milked twice daily and her calf was fed $1.9 \mathrm{~L}$ of her milk approximately $12 \mathrm{~h}$ apart. During the first $3 \mathrm{~d}$ of life, the only food the calf received was milk (or colostrum) from her dam. Any milk not voluntarily consumed by the calf was fed via an esophageal feeder so that intake of milk was equal for all calves. After the sixth feeding, a blood sample was taken into heparinized tubes.

\section{Analytical Methods}

Weekly feed samples were composited by month. The composited silage samples were lyophilized and all samples were ground through a 1-mm screen (Wiley mill, Arthur H. Thomas, Philadelphia, PA). Ground samples $(\mathrm{n}=4)$ for each feed were analyzed for $\mathrm{DM}\left(100^{\circ} \mathrm{C}\right.$ for $24 \mathrm{~h})$, ash $\left(600^{\circ} \mathrm{C}\right.$ muffle oven overnight), NDF (Ankom 200 Fiber Analyzer, Ankom Technology, Fairport, NY) with sodium sulfite and amylase (Ankom \#FAA), $\mathrm{CP}$ (Kjeldahl $\mathrm{N} \times 6.25$ ), and minerals by inductively coupled plasma spectrometry after nitric-perchloric acid digestion (concentrates) or oven-ashing (forages). A single composited sample of each feed was analyzed in triplicate for $\alpha$-tocopherol using the HPLC method described below after saponification (Indyk, 1988).

Neutrophil phagocytosis and intracellular kill of Escherichia coli 487 were measured by modifications of the fluorochrome assay (Goldner et al., 1983). Briefly, bacteria were cultured to a stationary phase of growth, washed, and opsonized in 10\% heat-inactivated serum for 20 min (Hogan et al., 1992). Suspensions of neutrophils and opsonized bacteria were added to tubes in a 1:2 (neutrophils:bacteria $\mathrm{cfu}$ ) ratio and incubated at $100 \mathrm{rpm}$ for $90 \mathrm{~min}$. Percentage neutrophils phagocytizing was calculated as the number of neutrophils with at least one intracellular bacteria divided by total number of neutrophils $\times 100$. Bacterial kill was calculated as number of dead intracellular bacteria divided by total number of intracellular bacteria $\times 100$. Assays were conducted in duplicate without technicians having knowledge of cow or treatment.

Plasma was assayed for cholesterol (Wako Cholesterol E \#439-17501, Wako Chemicals, Richmond, VA) and milk was assayed for fat (AOAC, 2000). To evaluate Se status, plasma collected at 7 DIM was assayed for Se (Koh and Benson, 1983) and concentrations averaged $0.084,0.086$, and $0.081(\mathrm{SE}=0.003) \mathrm{mg} / \mathrm{L}$ for control, RRR, and all-rac groups $(P>0.30)$, which are considered adequate. Total $\alpha$-tocopherol was extracted from $0.5 \mathrm{~mL}$ of plasma by adding $1 \mathrm{~mL}$ of ethanol (with $1 \% \mathrm{wt} / \mathrm{vol}$ ascorbic acid) followed by $5 \mathrm{~mL}$ of hexane (HPLC grade, Fisher Scientific, Fairlawn, NJ). The mixture was vortexed for $1 \mathrm{~min}$, centrifuged for $10 \mathrm{~min}$ at $1,000 \times g$, and then $4 \mathrm{~mL}$ of the hexane was removed, evaporated under $\mathrm{N}_{2}$, and redissolved in $0.4 \mathrm{~mL}$ of absolute ethanol. Milk and colostrum was extracted after saponification (Indyk, 1988) into $10 \mathrm{~mL}$ of petroleum ether (HPLC grade, Fisher Scientific) and shaken for $10 \mathrm{~min}$ at approximately $180 \mathrm{rpm}$. After centrifugation for $10 \mathrm{~min}$ at $1,000 \times g, 5 \mathrm{~mL}$ of the top layer was removed, evaporated under $\mathrm{N}_{2}$, and dissolved in $0.5 \mathrm{~mL}$ of absolute ethanol. Neutrophils were thawed, refrozen, thawed again, and then centrifuged at 27,000 $\times g$ for $15 \mathrm{~min}$ at $10^{\circ} \mathrm{C}$. The pellet was suspended in $1 \mathrm{~mL}$ of a solution of 76:24 ethanol:water [which also contained $1 \%$ (wt/vol) ascorbic acid]. Glass beads were added, samples vortexed for $1 \mathrm{~min}$, and then extracted with $4.9 \mathrm{~mL}$ of a mix of $68 \%$ ascorbic acid solution (1\% wt/ vol ascorbic acid; $70 \% \mathrm{vol} / \mathrm{vol}$ methanol, $30 \% \mathrm{vol} / \mathrm{vol}$ water) and $32 \%$ chloroform. After vortexing for $1 \mathrm{~min}$, $1.55 \mathrm{~mL}$ of chloroform was added and vortexed another $30 \mathrm{~s}$; then, $1.55 \mathrm{~mL}$ of water was added and vortexed for another $30 \mathrm{~s}$ (Bligh and Dyer, 1959). The solution was centrifuged at $3,000 \times g$ for 10 min at $10^{\circ} \mathrm{C}$ and a portion of the chloroform layer was removed, evaporated under $\mathrm{N}_{2}$, and redissolved in $0.3 \mathrm{~mL}$ of ethanol.

The ethanol extract from all samples was injected (100 $\mu \mathrm{L}$ ) into an HPLC equipped with a $25 \mathrm{~cm} \times 4.6 \mathrm{~mm}$, 5 - $\mu \mathrm{m}$ reverse phase column (Supelcosil LC-18, Supelco, Bellefonte, PA). The solvent was 92:8 methanol:water (HPLC grade, Fisher Scientific) that changed linearly to $100 \%$ methanol over $10 \mathrm{~min}$ at a flow rate of 1.8 $\mathrm{mL} / \mathrm{min}$. For neutrophil extracts, fluorescence detection was used (excitation at $290 \mathrm{~nm}$ and emission at $372 \mathrm{~nm}$ ) and UV detection (296 nm) was used for all other samples.

The concentrations of stereoisomers of $\alpha$-tocopherol were determined using an aliquot of the same extract used for total $\alpha$-tocopherol analysis. Extraction, methylation, and HPLC analysis was performed in a dark room under yellow light. An aliquot containing 0.3 to 3 $\mu \mathrm{g}$ of total $\alpha$-tocopherol was evaporated under $\mathrm{N}_{2}$ and derivatized to its methyl ester (Drotleff and Ternes, 2001). Briefly, the residue was dissolved in $50 \mu \mathrm{L}$ of ethylene glycol dimethyl ether (Sigma \#30,743-2, Sigma Diagnostics, St. Louis, MO), and $25 \mu \mathrm{L}$ of $50 \% \mathrm{KOH}$ (wt/vol) in water was added dropwise; then, the tube 
was filled with argon and capped immediately. This was repeated until all tubes were done. Then, $45 \mu \mathrm{L}$ of dimethylsulfate (Sigma \#D5279, Sigma Diagnostics) was added dropwise to a tube that was capped immediately. When all tubes were treated, they were shaken for $1 \mathrm{~h}$ at $180 \mathrm{rpm}$. The liquid was then evaporated to dryness under $\mathrm{N}_{2}$ in a heat block set at $37^{\circ} \mathrm{C} ; 0.1 \mathrm{~mL}$ of water (HPLC grade, Fisher Scientific) was added and the tubes were vortexed until the residue was dissolved. After vortexing, $1.5 \mathrm{~mL}$ of $\mathrm{n}$-heptane (99\%, HPLC grade, Burdick \& Jackson, Muskegon, MI) was added, the tubes were vortexed for $1 \mathrm{~min}$ and centrifuged for 10 min at $1,000 \times g$. An aliquot of the heptane layer was transferred to HPLC vials and $0.2 \mathrm{~mL}$ was injected into an HPLC equipped with a Chiracel OD-H column [4.6 $\times 250 \mathrm{~mm}, 5 \mu \mathrm{m}$, cellulose Tris (3,5-dimethylphenyl carbamate); Chiral Technologies Inc., West Chester, PA]. The mobile phase was a solution of approximately $0.02 \%$ 2-propanol (varied from 0.0065 to $0.03 \%$ based on resolution of the RRR peak) in n-heptane (99\%, HPLC grade, Burdick \& Jackson) with a flow rate of $0.95 \mathrm{~mL} / \mathrm{min}$. Fluorescence detection was used as described above.

$\alpha$-Tocopherol was separated into 5 isomer peaks; peak 1 was all $2 \mathrm{~S}$ isomers (SSS, SSR, SRS, SRR); peak 2 was RSS; peak 3 was RRS; peak 4 was RRR; and peak 5 was RSR. Identification of peaks was by comparison of retention time and total profile with external standards (DL- $\alpha$-tocopherol, Calbiochem, La Jolla, CA; RRR- $\alpha$-tocopherol standard, ADM, Decatur, IL) and the literature (Riss et al., 1994; Drotleff and Ternes, 2001). Isomers were quantified by using peak areas and external standards. An extinction coefficient of 71.0 (1\% solution with 1-cm light path) at $294 \mathrm{~nm}$ was used for confirmation of standard concentrations. A series of all-rac standards (Calbiochem) was methylated and analyzed during each run, and concentrations of the isomer peaks were calculated using a linear regression of these standards (assuming each isomer comprised $12.5 \%$ of the total $\alpha$-tocopherol). Because concentrations of individual isomers other than RRR were so low, areas of those isomers were summed. Peak 5 (RSR) was not included in that sum because it could not be consistently resolved from an interfering peak.

Intraassay $\mathrm{CV}$ for total $\alpha$-tocopherol in plasma, colostrum, and milk was 2.1, 2.4, and 4.5\%, respectively. For RRR $\alpha$-tocopherol, intraassay CV for plasma, colostrum, and milk was $6.0,4.2$, and $5.1 \%$, respectively.

\section{Statistical Analyses}

All data were analyzed using a model that included block (random, $11 \mathrm{df}$ ), treatment (fixed, $2 \mathrm{df}$ ), and er- ror (22 df) using PROC MIXED (SAS Institute, 2004). If treatment was significant $(P<0.05)$, the PDIFF option was used to separate means. For the calf data, sex of calf was initially included as a fixed effect but it had no effect $(P>0.40)$ and was removed from the final model.

\section{RESULTS AND DISCUSSION}

\section{Dietary Concentrations and Intake of Vitamin E}

The concentrations of $\alpha$-tocopherol in the corn silage and concentrates were low and moderate in the grass hay and alfalfa silage (Table 2). Tocopherol concentrations were generally similar to previous data except the concentration in corn silage was 3 to 8 times lower than reported elsewhere (Weiss et al., 1990b, 1997; O'Sullivan et al., 2002). Tocopherol is relatively unstable; therefore, wide variation in concentrations in feeds should be expected. The concentrations of vitamin $\mathrm{E}(\mathrm{IU} / \mathrm{kg})$ in the supplemented treatments were essentially equal, but because diets were formulated based on IU, diets with the RRR supplement contained less $\alpha$-tocopherol (mg/kg of diet) but more RRR $\alpha$-tocopherol than diets with the all-rac supplement.

Treatments had no effect on DMI during the pre- and postpartum periods (Table 3). Treatment average DMI was steady between -14 and $-7 \mathrm{~d}$ of lactation (averaged $11.5 \mathrm{~kg} / \mathrm{d}$ ) and then decreased about $25 \%$ the last $7 \mathrm{~d}$ of gestation (8.6 $\mathrm{kg}$ on the last day of gestation). Intake increased rapidly after parturition and averaged $16 \mathrm{~kg} / \mathrm{d}$ on 14 DIM (data not shown). Daily intake of vitamin E likely did not decrease greatly for cows fed supplemental vitamin E because they probably consumed most of the supplemental topdress. Vitamin E intake by control cows probably decreased about $25 \%$ (equivalent to approximately $60 \mathrm{mg}$ of $\alpha$-tocopherol/d) around parturition. During the pre- and postpartum periods cows fed the all-rac diets consumed about 1.3 times more $\alpha$-tocopherol/d than cows fed the RRR diets (Table 3) but cows fed the RRR diets consumed about 4 times more RRR $\alpha$-tocopherol than cows fed the allrac diets. All the $\alpha$-tocopherol consumed by cows fed the control and RRR diets was the RRR isomer but for cows fed the all-rac diets, $46 \%$ of the tocopherol was $2 \mathrm{~S}$ isomers, $11.4 \%$ was RRS, RSR, and RSS isomers each, and 20\% was RRR. Dietary recommendations for vitamin E intake for humans (IOM, 2000) gives the $2 \mathrm{~S}$ isomers no biological value. Using that definition, cows fed the control diets, the all-rac diets, and the RRR diets consumed about 230, 1,470, and 2,070 mg of vitamin $\mathrm{E} / \mathrm{d}$, respectively. 
Table 2. Measured concentrations of $\alpha$-tocopherol in feedstuffs and calculated concentrations in total diets (DM basis)

\begin{tabular}{|c|c|c|c|}
\hline \multirow[b]{2}{*}{ Item } & \multicolumn{2}{|c|}{$\alpha$-Tocopherol, mg/kg } & \\
\hline & Mean & $\mathrm{SD}^{1}$ & \\
\hline Corn silage & 8.6 & 0.53 & \\
\hline Grass hay & 45.2 & 0.7 & \\
\hline Alfalfa silage & 36.6 & 0.3 & \\
\hline Prefresh concentrate mix & 8.7 & 0.4 & \\
\hline Lactation concentrate mix & 5.3 & 0.4 & \\
\hline All-rac vitamin E topdress & 8,803 & 242.4 & \\
\hline \multirow[t]{2}{*}{ RRR vitamin E topdress } & 6,509 & 621.4 & \\
\hline & \multicolumn{2}{|c|}{$\alpha$-Tocopherol } & $R R R$-isomer ${ }^{2}$ \\
\hline Prefresh TMR & $\mathrm{mg} / \mathrm{kg}$ & $\mathrm{IU} / \mathrm{kg}^{3}$ & $\mathrm{mg} / \mathrm{kg}$ \\
\hline Control & 22.2 & 33.1 & 22.2 \\
\hline All-rac & 256.1 & 290.1 & 50.9 \\
\hline RRR & 195.0 & 290.6 & 195.0 \\
\hline \multicolumn{4}{|l|}{ Lactation TMR } \\
\hline Control & 14.1 & 21.0 & 14.1 \\
\hline All-rac & 202.4 & 228.0 & 37.4 \\
\hline RRR & 152.2 & 226.8 & 152.2 \\
\hline
\end{tabular}

${ }^{1} \mathrm{n}=3$.

${ }^{2}$ Concentration of $R R R$ was calculated by assuming all vitamin $\mathrm{E}$ in feedstuffs and in RRR supplement was $R R R$ and that $12.5 \%$ of vitamin $\mathrm{E}$ in all-rac supplement was $R R R$.

${ }^{3} \mathrm{IU}$ calculated as $1.49 \times \mathrm{mg}$ of $\alpha$-tocopherol from feedstuffs $+(1.49 \times \mathrm{mg}$ of $\alpha$-tocopherol from RRR topdress or $1.1 \times \mathrm{mg}$ of $\alpha$-tocopherol from all-rac topdress). Actual DMI and assumed intake of $285 \mathrm{~g}$ of topdress DM/d used to calculate TMR concentrations.

\section{Neutrophil Function}

Neutrophils from cows fed supplemental vitamin E had greater $(P<0.05)$ concentrations of $\alpha$-tocopherol than did neutrophils from cows not fed supplemental vitamin E (Table 4). Neutrophils from cows fed RRR had 1.26 times greater $(P<0.12)$ concentrations of $\alpha$-tocopherol than those from cows fed all-rac. That relative difference is similar to significant differences observed in plasma and milk (see below) but because variation is higher in the neutrophil assay, the difference was not significant.

The percentage of neutrophils that phagocytized bacteria averaged about $90 \%$ and was not affected by treatment; however, phagocytosis (number of bacteria per neutrophil) was increased $(P<0.05)$ by feeding all-

Table 3. Body weight and intakes of DM and $\alpha$-tocopherol by cows fed different sources of vitamin $\mathrm{E}^{1}$

\begin{tabular}{lcccc}
\hline Item & Control & RRR & All-rac & SE \\
\hline Prepartum (last 14 d of gestation) & & & & \\
BW, kg & 674 & 657 & 687 & 21.6 \\
DMI, kg/d & 11.5 & 10.7 & 10.7 & 0.55 \\
Vitamin E, IU/d & $383^{\mathrm{a}}$ & $3,118^{\mathrm{b}}$ & $3113^{\mathrm{b}}$ & 18.4 \\
$\alpha$-Tocopherol, mg/d & $256^{\mathrm{a}}$ & $2,090^{\mathrm{b}}$ & $2744^{\mathrm{c}}$ & 12.3 \\
$R R R$-tocopherol, mg/d & $256^{\mathrm{a}}$ & $2,090^{\mathrm{c}}$ & $551^{\mathrm{b}}$ & 12.3 \\
2R-tocopherol isomers, mg/d & $256^{\mathrm{a}}$ & $2,090^{\mathrm{c}}$ & $1,491^{\mathrm{b}}$ & 12.3 \\
Postpartum (first 14 d of lactation) & & & & \\
BW, kg & 608 & 602 & 615 & 17.3 \\
DMI, kg/d & 14.3 & 13.4 & 13.3 & 0.94 \\
Vitamin E, IU/d & $303^{\mathrm{a}}$ & $3,050^{\mathrm{b}}$ & $3,044^{\mathrm{b}}$ & 20.4 \\
$\alpha$-Tocopherol, mg/d & $202^{\mathrm{a}}$ & $2,047^{\mathrm{b}}$ & $2,699^{\mathrm{c}}$ & 14.5 \\
$R R R$-tocopherol, mg/d & $202^{\mathrm{a}}$ & $2,047^{\mathrm{c}}$ & $505^{\mathrm{b}}$ & 14.5 \\
2R-tocopherol isomers, mg/d & $202^{\mathrm{a}}$ & $2,047^{\mathrm{c}}$ & $1,445^{\mathrm{b}}$ & 14.5 \\
\hline
\end{tabular}

${ }^{\mathrm{a}-\mathrm{c}}$ Means in same row with different superscripts differ $(P<0.05)$.

${ }^{1}$ The vitamin $\mathrm{E}$ intakes were calculated by multiplying daily intake of $\alpha$-tocopherol from feedstuffs by 1.49 and adding the IU of vitamin E provided by $285 \mathrm{~g}$ of topdress DM. For the all-rac treatment the IU conversion factor was 1.1 and 1.49 for the RRR treatment. Tocopherol intakes were calculated by multiplying DMI by the concentration of tocopherol in the appropriate control diet and then adding the amount of tocopherol provided by the topdress. Intake of RRR isomer was calculated the same way except the tocopherol provided by the topdress in the all-rac treatment was multiplied by 0.125 . 
rac vitamin E. Previously, vitamin E supplementation of cows has not enhanced phagocytosis by their neutrophils (Gyang et al., 1984; Hogan et al., 1990, 1992). When bovine neutrophils were incubated in media containing all-rac $\alpha$-tocopherol, phagocytosis increased as the concentration of $\alpha$-tocopherol increased up to $0.5 \mathrm{mg} / \mathrm{L}$ of media. At the next greater concentration $(5 \mathrm{mg} / \mathrm{L})$ phagocytosis was markedly reduced (value was similar to that of the control with no supplemental vitamin E) and continued to decrease as $\alpha$-tocopherol concentrations increased (Ndiweni and Finch, 1996). The cells from cows fed RRR had the greatest concentration of $\alpha$-tocopherol, and perhaps the concentration was high enough to suppress phagocytosis. However, an injection of vitamin $\mathrm{E}$ to periparturient cows increased the concentration of $\alpha$-tocopherol in neutrophils to approximately $12 \mathrm{ng} / 10^{6}$ cells (more than twice the concentration measured in cells from cows fed RRR in this study) and did not affect phagocytosis (Hogan et al., 1992). The reason for the increased phagocytosis when cows were fed all-rac vitamin E but not RRR is not known.

The percentage of phagocytized bacteria that were killed averaged $85 \%$ and was not affected by treatment but because neutrophils from cows fed all-rac phagocytized more bacteria, the number of bacteria killed (i.e., the kill index) was greater $(P<0.05)$. Supplemental vitamin $\mathrm{E}$ has increased killing ability (measured as \% of bacteria killed) of neutrophils from cows and calves (Gyang et al., 1984; Hogan et al., 1990, 1992; Eicher et al., 1994), and we hypothesized that feeding RRR vitamin $\mathrm{E}$ would increase the tocopherol concentration of the neutrophils and enhance killing (Hogan et al., 1992). Hidiroglou et al. (1997) reported generally greater concentrations of $\alpha$-tocopherol in neutrophils from dairy cows fed RRR vitamin E compared with those fed all-rac but found no effect of treatment on superoxide or hydrogen peroxide release. Release of those chemi- cals by neutrophils can be related to killing ability but is not directly equivalent. However, the lack of treatment effect on bacterial kill (\%) in this study supports the data from Hidiroglou et al. (1997). In summary, supplemental all-rac vitamin E increased neutrophil tocopherol and stimulated phagocytosis resulting in increased number of killed bacteria. The RRR supplement also increased the concentration of $\alpha$-tocopherol in neutrophils (perhaps to a greater extent than did all-rac) but it had no effect on phagocytosis and kill.

\section{Plasma Tocopherol}

Concentrations of $\alpha$-tocopherol in plasma (Figure 1A) did not differ between treatments at $-14 \mathrm{~d}$ (before treatments started) but all treatments differed from each other $(P<0.01)$ at all other time points. Concentrations were lowest for cow fed the control diet, intermediate for cows fed all-rac, and greatest for cows fed the RRR supplement. The change in concentrations over time followed the well-established pattern (Weiss et al., 1990a) of reaching a nadir shortly after calving. The concentration of $\alpha$-tocopherol in control cows decreased $71 \%$ from -14 to 3 DIM, $48 \%$ for cows fed 2,500 IU/d of all-rac vitamin E, and 35\% for cows fed 2,500 IU of RRR vitamin E. Feeding 4,000 IU/d of vitamin $\mathrm{E}$ (from all-rac tocopheryl acetate) prevented the decrease in plasma $\alpha$-tocopherol concentrations normally observed in periparturient cows (Weiss et al., 1997) but feeding 1,000 to $3,000 \mathrm{IU} / \mathrm{d}$ of vitamin E from all-rac supplements (Weiss et al., 1997; Politis et al., 2004) or 1,000 $\mathrm{IU} / \mathrm{d}$ of vitamin $\mathrm{E}$ from RRR $\alpha$-tocopherol (Meglia et al., 2006) did not. Plasma tocopherol and cholesterol are associated with lipoproteins; therefore, tocopherol is often expressed relative to cholesterol concentrations to adjust for variation in lipoprotein concentrations (Weiss et al., 1992; Herdt and Smith, 1996). In this study, concentrations of plasma $\alpha$-tocopherol per unit

Table 4. Effect of supplemental vitamin E on the function and concentration of total $\alpha$-tocopherol in blood neutrophils collected from cows at 3 DIM

\begin{tabular}{|c|c|c|c|c|}
\hline Item & Control & $\mathrm{RRR}$ & All-rac & $\mathrm{SE}$ \\
\hline $\begin{array}{l}\alpha \text {-Tocopherol, ng/ } / 10^{6} \text { cells } \\
\text { Neutrophil function }\end{array}$ & $2.71^{\mathrm{a}}$ & $5.84^{\mathrm{b}}$ & $4.62^{\mathrm{b}}$ & 0.61 \\
\hline Positive cells, ${ }^{1} \%$ & 90 & 90 & 91 & 0.7 \\
\hline Bacteria/neutrophil, ${ }^{2} \mathrm{n}$ & $5.08^{\mathrm{a}}$ & $4.92^{\mathrm{a}}$ & $5.68^{\mathrm{b}}$ & 0.18 \\
\hline Kill, ${ }^{3} \%$ & 86 & 84 & 84 & 1.5 \\
\hline Kill index ${ }^{4}$ & $3.94^{\mathrm{a}}$ & $3.72^{\mathrm{a}}$ & $4.34^{\mathrm{b}}$ & 0.14 \\
\hline
\end{tabular}



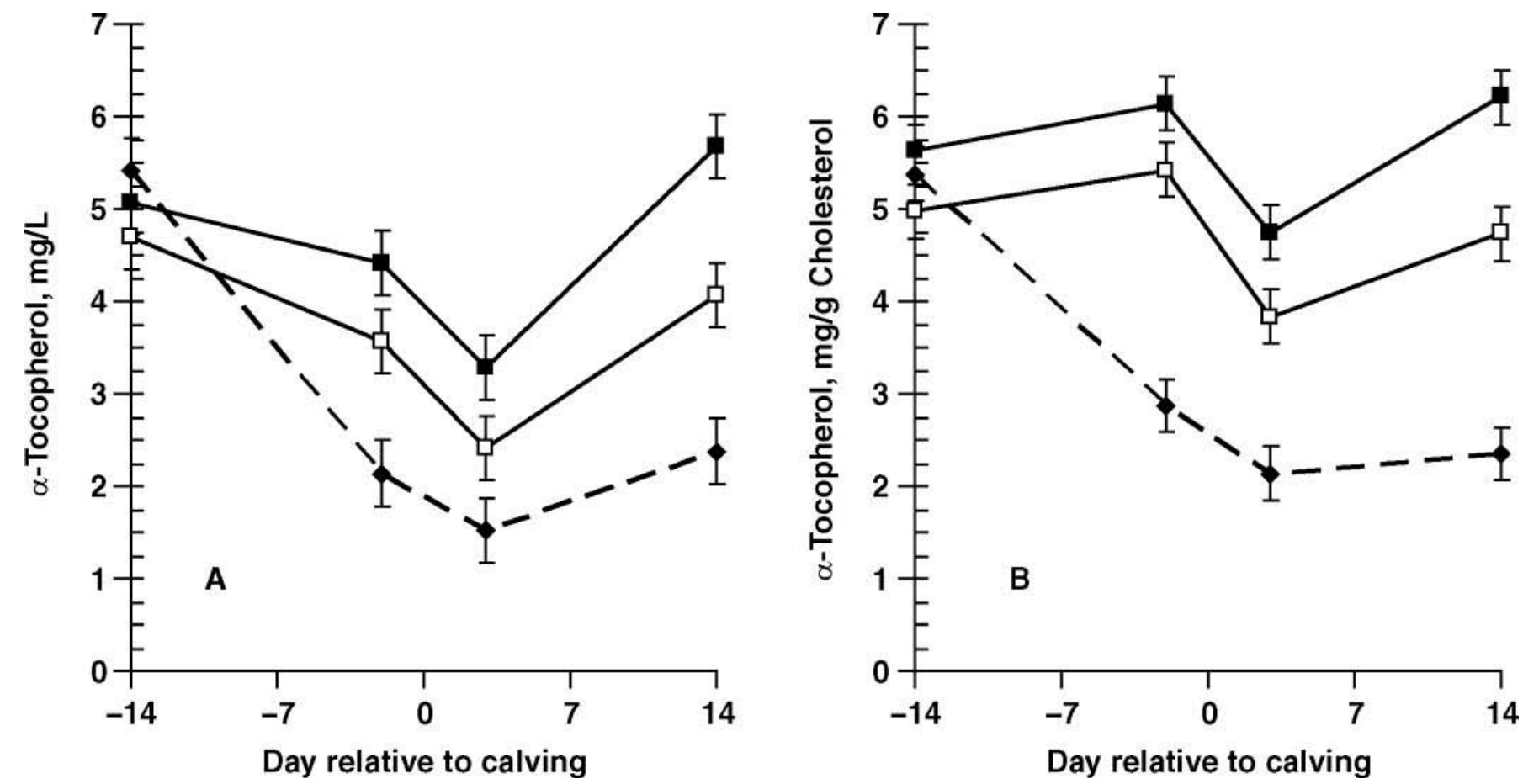

Figure 1. Concentrations of total $\alpha$-tocopherol per liter (A) and per gram of cholesterol (B) in plasma of cows fed no supplemental vitamin $\mathrm{E}$ (dashed line) or $2,500 \mathrm{IU} / \mathrm{d}$ of supplemental vitamin $\mathrm{E}$ from either all-rac tocopheryl acetate (open squares) or RRR tocopherol (closed squares). Treatments started immediately after the $-14 \mathrm{~d}$ samples were taken. Within a sampling day, all means differ $(P<0.01)$ from each other (excluding $-14 \mathrm{~d}$ ).

of cholesterol changed less over time than did concentrations expressed per milliliter (Figure 1B) but because cholesterol was not affected by treatment (data not shown) treatment effects were the same.

Although cows in the RRR and all-rac treatments consumed essentially the same amount (in IU) of vitamin $\mathrm{E} / \mathrm{d}$, plasma concentrations $(\mathrm{mg} / \mathrm{L}$ ) of $\alpha$-tocopherol were $1.2(-2 \mathrm{DIM})$ to $1.4(14 \mathrm{DIM})$ times greater in cows fed RRR vitamin E. When concentrations were expressed relative to cholesterol, they were 1.1 to 1.3 times greater. In previous research with periparturient dairy cows, plasma concentrations of $\alpha$-tocopherol $(\mathrm{mg} / \mathrm{L})$ were 1.1 to 1.4 times greater when cows were fed 1,000 IU/d of RRR $\alpha$-tocopherol compared with 1,000 IU of all-rac vitamin E (Hidiroglou et al., 1997; Meglia et al., 2006).

\section{Milk Tocopherol}

Milk yields from 3 to 14 DIM did not differ between treatments (Table 5). Yields of colostrum and milk produced in the first 6 milkings are not reported because cows were not necessarily completely milked out. The concentrations of fat in colostrum, transition milk, and milk were not affected by treatment. Concentrations of $\alpha$-tocopherol in colostrum, transition milk, and milk were greatest for cows fed RRR, intermediate for cows fed all-rac, and lowest for cows fed no supplemental vitamin E (Table 5). The differences in concentrations of tocopherol in colostrum and milk between unsupplemented cows and those supplemented with all-rac vitamin $\mathrm{E}$ were within the range of most previous studies (Weiss et al., 1990b, 1992, 1997; Baldi et al., 2000). Concentrations of $\alpha$-tocopherol in milk was 1.24 to 1.43 times greater for cows fed the RRR supplement compared with cows fed the all-rac supplement but concentrations differed statistically $(P<0.05)$ only for colostrum and milk. The relative differences in $\alpha$-tocopherol concentrations between cows fed RRR and all-rac are essentially the same as those reported by Meglia et al. (2006). Treatment differences were essentially the same when milk tocopherol concentrations were expressed relative to milk fat (Table 5).

\section{Calf Plasma Tocopherol}

The concentration of $\alpha$-tocopherol in plasma from calves before they consumed colostrum was extremely low and not affected by the treatment imposed on their dams (Table 6). After consuming 6 feedings of colostrum and transition milk, plasma concentrations of $\alpha$-tocopherol increased markedly and were affected 
Table 5. Effect of type of supplemental vitamin E on $\alpha$-tocopherol and fat concentrations in colostrum and milk $^{1}$

\begin{tabular}{|c|c|c|c|c|}
\hline Item & Control & RRR & All-rac & SE \\
\hline \multicolumn{5}{|l|}{ Fat, $\%$} \\
\hline Colostrum & 6.37 & 6.16 & 6.18 & 0.77 \\
\hline Transition milk & 6.25 & 5.97 & 5.63 & 0.40 \\
\hline Milk & 4.88 & 4.72 & 4.70 & 0.32 \\
\hline \multicolumn{5}{|l|}{$\alpha$-Tocopherol, mg/L } \\
\hline Colostrum & $6.79^{\mathrm{a}}$ & $13.91^{\mathrm{c}}$ & $10.45^{\mathrm{b}}$ & 1.05 \\
\hline Transition milk & $2.19^{\mathrm{a}}$ & $4.21^{\mathrm{b}}$ & $3.39^{\mathrm{b}}$ & 0.42 \\
\hline Milk & $0.41^{\mathrm{a}}$ & $1.29^{\mathrm{c}}$ & $0.90^{\mathrm{b}}$ & 0.088 \\
\hline \multicolumn{5}{|l|}{$\alpha$-Tocopherol, $\mathrm{mg} / \mathrm{kg}$ of fat } \\
\hline Colostrum & $115.0^{\mathrm{a}}$ & $236.7^{\text {bd }}$ & $190.2^{\text {be }}$ & 19.1 \\
\hline Transition milk & $35.6^{\mathrm{a}}$ & $73.2^{\mathrm{bd}}$ & $58.3^{\text {be }}$ & 6.24 \\
\hline Milk & $8.8^{\mathrm{a}}$ & $27.3^{\mathrm{c}}$ & $19.8^{\mathrm{b}}$ & 1.69 \\
\hline
\end{tabular}

${ }^{\mathrm{a}-\mathrm{c}}$ Means in same row with different superscripts differ $(P<0.05)$.

${ }^{\mathrm{d}, \mathrm{e}}$ Means differ within a row $(P<0.10)$.

${ }^{1}$ Colostrum is the first milking following parturition; transition milk is a composited sample (by weight) of the second through sixth milking after parturition; and milk is a composited (a.m. and p.m.) sample of milk produced at 14 DIM.

by treatment. Placental transfer of $\alpha$-tocopherol is extremely limited (Van Saun et al., 1989) and calves are born with very low concentrations of $\alpha$-tocopherol, which then increase after colostrum is consumed (Nonnecke et al., 1999). After 6 feedings, plasma $\alpha$-tocopherol in calves from cows fed all-rac was 1.26 times greater than the concentration in calves from control cows but that was not statistically different $(P>0.22)$. However, the concentration of tocopherol in the colostrum and milk consumed by calves on the all-rac treatment was 1.55 times greater $(P<0.01)$ than milk from unsupplemented cows (Table 6). Vitamin E supplementation to beef cows (600 to 1,000 IU/d of all-rac tocopheryl acetate during the last month of gestation) had mixed effects on $\alpha$-tocopherol concentrations in plasma of their calves taken 24 to $48 \mathrm{~h}$ after birth (Bass et al., 2001). In that study, supplementing multiparous cows fed hay-based diets with 1,000 IU/d vitamin E increased plasma $\alpha$-tocopherol concentrations in their calves, but no effects were observed with calves from primiparous animals and no effect was observed when cows were fed a pasture-based diet supplemented with $600 \mathrm{IU} / \mathrm{d}$ of vitamin E. After 6 feedings, calves from cows fed the RRR supplement had plasma concentrations of $\alpha$-tocopherol that were 1.8 times greater $(P<$ $0.01)$ than the unsupplemented group and 1.4 times greater $(P<0.05)$ than the all-rac group. The average milk consumed by calves in the RRR group had $2.0(P$ $<0.01)$ and $1.3(P<0.05)$ times as much $\alpha$-tocopherol as the unsupplemented and all-rac groups, respectively. Across all treatments, the concentration of total $\alpha$-tocopherol in the milk consumed by the calves and

Table 6. Effect of source of supplemental vitamin E fed to peripartum cows on plasma $\alpha$-tocopherol in their calves and in milk fed to the calf

\begin{tabular}{lcccl}
\hline Item & Control & RRR & All-rac & SE \\
\hline At birth & & & & \\
$\quad \alpha$-Tocopherol, mg/L & 0.27 & 0.32 & 0.33 & 0.03 \\
Cholesterol, mg/dL & 20.5 & 21.4 & 23.5 & 1.6 \\
$\quad \alpha$-Tocopherol, mg/g of cholesterol & 1.35 & 1.48 & 1.39 & 0.09 \\
After 6 feedings & & & & \\
$\alpha$-Tocopherol, mg/L & $1.15^{\mathrm{a}}$ & $2.06^{\mathrm{b}}$ & $1.45^{\mathrm{a}}$ & 0.18 \\
Cholesterol, mg/dL & 56.4 & 58.5 & 59.3 & 3.5 \\
$\alpha$-Tocopherol, mg/g of cholesterol & $1.98^{\mathrm{a}}$ & $3.48^{\mathrm{b}}$ & $2.49^{\mathrm{a}}$ & 0.27 \\
Milk & & & & \\
$\alpha$-Tocopherol, mg/L & $4.13^{\mathrm{a}}$ & $8.37^{\mathrm{c}}$ & $6.41^{\mathrm{b}}$ & 0.57 \\
RRR-tocopherol, mg/L & $3.75^{\mathrm{a}}$ & $7.43^{\mathrm{b}}$ & $4.35^{\mathrm{a}}$ & 0.48 \\
2R-tocopherol, mg/L & $3.98^{\mathrm{a}}$ & $8.15^{\mathrm{c}}$ & $6.09^{\mathrm{b}}$ & 0.53 \\
\hline
\end{tabular}

${ }^{\mathrm{a}-\mathrm{c}}$ Means in same row with different superscripts differ $(P<0.05)$.

${ }^{1}$ Calves were fed only colostrum and milk from their dams for the first 6 feedings $(3 \mathrm{~d})$.

${ }^{2}$ Weighted average (based on amount fed to calves) of samples from the first 6 milkings following parturition. 
the concentration of RRR $\alpha$-tocopherol in milk was correlated with the concentration of plasma tocopherol of calves after 6 feedings $\left(\mathrm{r}^{2}=0.30\right.$ and 0.29 , respectively; $P<0.001$, data not shown).

\section{Tocopherol Isomers}

The only $\alpha$-tocopherol isomer consumed by cows fed the control and RRR treatments was RRR but their plasma and milk contained low but measurable concentrations of other isomers (Table 7). All cows on this experiment consumed all-rac vitamin E essentially from birth until they started this experiment. The isomers other than RRR (i.e., non-RRR) found in samples from these animals probably reflect previous consumption of all-rac vitamin E. A previous study with periparturient dairy cows (Meglia et al., 2006) found essentially no residual non-RRR isomers in plasma and milk $(<3 \%$ of total isomers) after removing all-rac tocopheryl acetate from the diet and replacing it with supplemental RRR $\alpha$-tocopherol acetate (1,000 IU of vitamin $\mathrm{E} / \mathrm{d})$ or no supplemental vitamin $\mathrm{E}$. When rats stopped being fed a diet with all-rac vitamin $\mathrm{E}$ and were fed diets with only RRR $\alpha$-tocopherol (supplementation rates ranged from 25 to $200 \mathrm{mg}$ of tocopherol $/ \mathrm{kg}$ of diet) for 10 $\mathrm{d}$, between $8 \%(200 \mathrm{mg} / \mathrm{kg}$ supplementation rate) and $30 \%(25 \mathrm{mg} / \mathrm{kg}$ rate $)$ of the isomers in plasma were non-RRR (Jensen et al., 2006).
The concentrations of non-RRR isomers in all sample types were greater $(P<0.01)$ for the all-rac group than the other 2 groups (Table 7 ) indicating that at least a portion of these isomers were absorbed. The concentrations of RRR in all sample types did not differ $(P>0.25)$ between the unsupplemented group and the all-rac group but were consistently greater $(P$ $<0.01)$ for the RRR group. Cows in the RRR group consumed 1,500 to $1,800 \mathrm{mg} / \mathrm{d}$ more RRR $\alpha$-tocopherol than cows in the other 2 groups but cows in the allrac group consumed only about $300 \mathrm{mg} / \mathrm{d}$ more RRR $\alpha$-tocopherol than the unsupplemented group (Table $3)$. The difference in RRR intake between the all-rac and unsupplemented groups may have been inadequate to produce statistically different concentrations of RRR $\alpha$-tocopherol in plasma and milk. Another possible reason is that efficiency of absorption of specific isomers varies with intake of vitamin E. Jensen et al. (2006) showed that the concentration of RRR $\alpha$-tocopherol in plasma did not increase linearly as intake of all-rac vitamin $\mathrm{E}$ by rats increased.

Supplementing RRR $\alpha$-tocopherol increased the relative enrichment of the RRR compared with cows fed no supplemental vitamin E. The RRR isomer comprised about $85 \%$ of the peak area of all isomers for plasma and milk samples from unsupplemented cows and their calves and 87 to $94 \%$ of all isomers for the RRR group (Table 7). The small difference between the unsupplemented group and the RRR group was caused by dilu-

Table 7. Effect of source of supplemental vitamin $\mathrm{E}$ on concentrations $(\mathrm{mg} / \mathrm{L})$ of $\alpha$-tocopherol isomers in plasma and milk

\begin{tabular}{|c|c|c|c|c|}
\hline Item & Control & RRR & All-rac & $\mathrm{SE}$ \\
\hline \multicolumn{5}{|c|}{ Cow plasma -2 DIM } \\
\hline $\mathrm{RRR}$ & $1.79^{\mathrm{a}}$ & $3.83^{\mathrm{b}}$ & $2.04^{\mathrm{a}}$ & 0.21 \\
\hline Other $^{1}$ & $0.31^{\mathrm{a}}$ & $0.30^{\mathrm{a}}$ & $1.10^{\mathrm{b}}$ & 0.09 \\
\hline $2 \mathrm{~S}$ isomers & $\mathrm{BD}^{2}$ & $\mathrm{BD}$ & 0.25 & $0.08^{3}$ \\
\hline \multicolumn{5}{|c|}{ Cow plasma 14 DIM } \\
\hline RRR & $2.00^{\mathrm{a}}$ & $4.78^{\mathrm{b}}$ & $2.04^{\mathrm{a}}$ & 0.28 \\
\hline Other & $0.23^{\mathrm{a}}$ & $0.29^{\mathrm{a}}$ & $1.41^{\mathrm{b}}$ & 0.08 \\
\hline $2 \mathrm{~S}$ & $\mathrm{BD}$ & $\mathrm{BD}$ & 0.23 & $0.13^{3}$ \\
\hline \multicolumn{5}{|c|}{ Calf plasma (after 6 feedings of dam's colostrum and milk) } \\
\hline $\mathrm{RRR}$ & $1.32^{\mathrm{a}}$ & $1.84^{\mathrm{b}}$ & $1.21^{\mathrm{a}}$ & 0.16 \\
\hline Other & $0.20^{\mathrm{a}}$ & $0.21^{\mathrm{a}}$ & $0.35^{\mathrm{b}}$ & 0.029 \\
\hline $2 \mathrm{~S}$ & $\mathrm{BD}$ & $\mathrm{BD}$ & 0.03 & $0.01^{3}$ \\
\hline \multicolumn{5}{|c|}{ Colostrum (first milking) } \\
\hline $\mathrm{RRR}$ & $5.92^{\mathrm{a}}$ & $12.29^{\mathrm{b}}$ & $7.30^{\mathrm{a}}$ & 0.90 \\
\hline Other & $1.20^{\mathrm{a}}$ & $1.88^{\mathrm{a}}$ & $3.11^{\mathrm{b}}$ & 0.23 \\
\hline $2 \mathrm{~S}$ & 0.29 & 0.38 & 0.57 & 0.08 \\
\hline \multicolumn{5}{|c|}{ Transition milk (composite of second through sixth milking) } \\
\hline RRR & $2.01^{\mathrm{a}}$ & $3.79^{\mathrm{b}}$ & $2.22^{\mathrm{a}}$ & 0.33 \\
\hline Other & $0.36^{\mathrm{a}}$ & $0.42^{\mathrm{a}}$ & $0.94^{\mathrm{b}}$ & 0.10 \\
\hline $2 \mathrm{~S}$ & 0.05 & 0.10 & 0.14 & 0.02 \\
\hline
\end{tabular}

${ }^{\mathrm{a}-\mathrm{c}}$ Means in same row with different superscripts differ $(P<0.05)$.

${ }^{1}$ Other isomers include SSS, SSR, SRS, SRR, RSS, RSR, and RRS $\alpha$-tocopherol.

${ }^{2} \mathrm{BD}=$ below detection.

${ }^{3}$ Number shown is standard deviation of values from the all-rac treatment only. 
tion (i.e., increased concentrations of RRR) because the actual concentrations of non-RRR isomers in plasma and milk samples did not differ $(P>0.30)$. For the all-rac group, the RRR isomer comprised 60 to $65 \%$ of the peak area in cow plasma, $70 \%$ for colostrum and transition milk, and $78 \%$ for calf plasma. Relative to dietary RRR (i.e., $20 \%$ of all isomers; Table 3), plasma was enriched about 3.1 times (i.e., 62/20) and milk was enriched about 3.5 times. Meglia et al. (2006) reported a greater relative concentration of RRR in plasma and milk (approximately $90 \%$ of the isomers) when periparturient cows were fed supplemental all-rac tocopheryl acetate. However, because the supplementation rate was lower $(1,000 \mathrm{IU} / \mathrm{d}), \mathrm{RRR}$ was about $47 \%$ of all isomers in that diet (compared with $20 \%$ in this experiment). In that study enrichment of RRR in plasma and milk relative to diet was 1.9 times. In rats fed all-rac vitamin E, relative enrichment of RRR (\% of RRR found in tissue divided by $\%$ of RRR in the diet) in plasma averaged about 1.7 and about 1.3 for liver (Jensen et al., 2006). In chickens fed all-rac vitamin E, relative enrichment averaged about 1.3 times for liver and thigh muscle (Cortinas et al., 2004).

The diet consumed by the calves consisted entirely of milk produced by their dams. For the unsupplemented, RRR, and all-rac groups, RRR comprised 85, 88, and $70 \%$, respectively, of all tocopherol isomers in the milk fed to the calves (weighted average of colostrum and transition milk). The RRR comprised 85, 90, and $77 \%$ of isomers in the plasma of calves (after 6 feedings), which was about the same distribution as found in plasma from cows fed the control, all-rac, and RRR treatments. However, enrichment relative to dietary vitamin $\mathrm{E}$ differed greatly between cows and calves in the all-rac treatment (3.1 for cows and 1.1 for calves). The likely reason for that difference is the diet for the all-rac calves (i.e., milk) was already highly enriched in RRR and plasma could not be enriched much more.

In all sample types, the greatest discrimination occurred with the $2 \mathrm{~S}$ isomers. Cows in the control and RRR groups consumed no $2 \mathrm{~S}$ isomers during this experiment and no $2 \mathrm{~S}$ isomers were detected in their plasma (data not shown). Approximately $45 \%$ of the vitamin $\mathrm{E}$ consumed by cows in the all-rac group was the $2 \mathrm{~S}$ isomers but only $8 \%$ of the isomers in plasma were $2 \mathrm{~S}$ (enrichment relative to diet $=0.18$ ). For all treatments, about $4 \%$ of the isomers in colostrum and milk were $2 \mathrm{~S}$ but no $2 \mathrm{~S}$ isomers were found in plasma from calves. Depending on tissue and animal species previously reported (Cortinas et al., 2004; Jensen et al., 2006; Meglia et al., 2006) relative enrichments for $2 \mathrm{~S}$ isomers ranged from about 0.02 (cows) to about 0.6 (poultry).

\section{Bioavailability}

The most recent recommended daily allowance for vitamin E (IOM, 2000) limited the definition of vitamin $\mathrm{E}$ to include only $2 \mathrm{R}$ isomers (i.e., RRR, RRS, RSR, and RSS) for humans. Therefore, $1 \mathrm{mg}$ of all-rac $\alpha$-tocopherol was set as equivalent to $0.5 \mathrm{mg}$ of $\mathrm{RRR}$ $\alpha$-tocopherol, but for domestic animals (e.g., NRC, 2001) the USP conversion factor is used (i.e., $1 \mathrm{mg}$ of all-rac-tocopherol is equivalent to $0.74 \mathrm{mg}$ of RRR tocopherol). The USP conversion factor equating all-rac $\alpha$-tocopherol to RRR $\alpha$-tocopherol was derived from a series of experiments that used fetal resorption by rats as the response criteria (Harris and Ludwig, 1949), and the calculated conversion factors varied widely in that paper. Blatt et al. (2004) argued that the equivalency factor between RRR and all-rac is not constant and should be dose-dependent. Subsequent data (Jensen et al., 2006) derived from rats generally support that interpretation.

Concentrations of $\alpha$-tocopherol in plasma, milk, neutrophils, and calf plasma was 1.24 to 1.43 times greater for RRR treatment than for all-rac treatment and averaged about 1.3 times higher (Table 8). Although cows in the 2 treatments consumed the same amount of vitamin $\mathrm{E}$ (IU/d), cows fed the RRR treatment consumed only 0.76 times as much $\alpha$-tocopherol as cows fed the all-rac treatment (Table 3). When differences in concentrations are adjusted to account for the differences in $\alpha$-tocopherol intake [(concentration from RRR treatment/concentration from all-rac treatment)/ ( $\alpha$-tocopherol intake by RRR treatment $/ \alpha$-tocopherol intake by all-rac treatment)], the concentrations of $\alpha$-tocopherol per unit of $\alpha$-tocopherol consumed were 1.63 to 1.84 times greater when cows were fed RRR (Table 8). The concentration of $\alpha$-tocopherol in calf plasma per unit of $\alpha$-tocopherol consumed for the RRR group was essentially equal to that of the all-rac group (Table 8). The reason for the difference between cows and calves is the isomers that comprised the consumed $\alpha$-tocopherol. Intake of total $\alpha$-tocopherol by cows fed RRR was 0.76 times as much for cows fed all-rac. Because $50 \%$ of all-rac vitamin $\mathrm{E}$ is composed of $2 \mathrm{R}$ isomers but $100 \%$ of the RRR vitamin $\mathrm{E}$ is $2 \mathrm{R}$, intake of the $2 \mathrm{R}$ isomers was 1.4 times greater for cows fed RRR (Tables 3 and 8). For calves, almost all the $\alpha$-tocopherol in milk was 2R isomers (Tables 6 and 8); therefore, intakes of total $\alpha$-tocopherol and $2 \mathrm{R} \alpha$-tocopherol were essentially the same (i.e., calves from cows fed RRR consumed about 1.3 times more total $\alpha$-tocopherol and 1.3 times more $2 \mathrm{R} \alpha$-tocopherol than calves from cows fed all-rac).

To determine whether the IOM (2000) definition of vitamin $\mathrm{E}$ is appropriate for dairy cows, concentrations 
Table 8. Relative intakes of vitamin $\mathrm{E}$ and tocopherol and relative concentrations of $\alpha$-tocopherol from cows fed RRR supplement or cows fed all-rac supplement

\begin{tabular}{|c|c|c|c|}
\hline \multirow[b]{2}{*}{ Item } & \multirow[b]{2}{*}{ Ratio $^{1}$} & \multicolumn{2}{|c|}{ Intake-adjusted ratio $^{2}$} \\
\hline & & $\alpha$-Tocopherol & $2-\mathrm{R}$ \\
\hline \multicolumn{4}{|c|}{ Intakes (averaged across pre- and postpartum periods) } \\
\hline Vitamin E, IU/d & 1.00 & - & - \\
\hline$\alpha$-Tocopherol, mg/d & $0.76^{*}$ & - & - \\
\hline 2-R tocopherol, $\mathrm{mg} / \mathrm{d}$ & $1.41^{*}$ & - & - \\
\hline RRR tocopherol, $\mathrm{mg} / \mathrm{d}$ & $3.92^{*}$ & - & - \\
\hline \multicolumn{4}{|l|}{ Cow } \\
\hline Plasma $\alpha$-tocopherol, -2 DIM & $1.24^{*}$ & $1.63^{*}$ & 0.88 \\
\hline Plasma $\alpha$-tocopherol, 3 DIM & $1.36^{*}$ & $1.79^{*}$ & 0.96 \\
\hline Plasma $\alpha$-tocopherol, 14 DIM & $1.40^{*}$ & $1.84^{*}$ & 0.99 \\
\hline Neutrophil $\alpha$-tocopherol & 1.26 & $1.66^{*}$ & 0.89 \\
\hline Colostrum $\alpha$-tocopherol & $1.33^{*}$ & $1.75^{*}$ & 0.94 \\
\hline Transition milk $\alpha$-tocopherol & 1.24 & $1.63^{*}$ & 0.88 \\
\hline Milk $\alpha$-tocopherol & $1.43^{*}$ & $1.88^{*}$ & 1.01 \\
\hline \multicolumn{4}{|l|}{ Intakes by calves } \\
\hline$\alpha$-Tocopherol, mg/d & $1.30^{*}$ & - & - \\
\hline 2R tocopherol, mg/d & $1.34^{*}$ & - & - \\
\hline RRR tocopherol, mg/d & $1.71^{*}$ & - & - \\
\hline Calf plasma $\alpha$-tocopherol (after 6 feedings) & $1.42^{*}$ & 1.09 & 1.06 \\
\hline \multicolumn{4}{|c|}{$\begin{array}{l}{ }^{1} \text { Ratio }=\text { mean concentration (or intake) for RRR treatment divided by mean of all-rac group (see Tables } \\
5 \text {, and } 6 \text { for original data). }\end{array}$} \\
\hline \multicolumn{4}{|c|}{$\begin{array}{l}{ }^{2} \text { Ratio for concentrations divided by ratio for intakes of different types of vitamin } \mathrm{E} \text { (i.e., } 0.76 \text { and } 1.41 \text { for } \\
\alpha \text {-tocopherol and } 2 \text { - } \mathrm{R} \text { for cows and } 1.30 \text { and } 1.34 \text { for calves). }\end{array}$} \\
\hline \multicolumn{4}{|c|}{$\begin{array}{l}\text { *Concentration or intake for RRR treatment differed from all-rac group }(P<0.05) \text {. See Tables } 3,5 \text {, and } 6 \text { for } \\
\text { original data. }\end{array}$} \\
\hline
\end{tabular}

of $\alpha$-tocopherol in plasma, milk, and neutrophils were expressed relative to intake of only the $2 \mathrm{R}$ isomers $[(\alpha$-tocopherol concentration in $\mathrm{RRR}$ treatment $/ \alpha-$ tocopherol concentration in all-rac treatment $) /(2 \mathrm{R}$ intake by RRR treatment/2R intake by all-rac treatment)]. No differences $(P>0.20)$ were observed between the vitamin $\mathrm{E}$ treatments for concentration data when adjusted for differences in intake of $2 \mathrm{R}$ isomers (Table 8). The concentration of $\alpha$-tocopherol in plasma and milk per unit of $2 \mathrm{R} \alpha$-tocopherol consumed in cows fed RRR supplement were 0.88 to 1.01 times that for cows fed all-rac supplements. The concentration of $\alpha$-tocopherol in calf plasma per unit of $2 \mathrm{R} \alpha$-tocopherol consumed by the calves fed milk from cows fed RRR supplement was 1.06 times that of calves from all-rac cows. The primary reason for the difference in $\alpha$-tocopherol concentrations between treatments was the difference in intake of $2 \mathrm{R}$ isomers. In other experiments (Eicher et al., 1997; Hidiroglou et al., 1997; Meglia et al., 2006), cattle fed $R R R$ vitamin $E$ had concentrations of $\alpha$-tocopherol in plasma, red blood cells, or neutrophils that were 1.10 to 1.4 times greater than in cattle fed an equal (IU basis) concentration of all-rac vitamin E. When concentrations from those papers were expressed relative to the calculated intake of $2 \mathrm{R}$ isomers they were essentially equal for cows fed RRR or all-rac. Therefore, based on concentrations of $\alpha$-tocopherol in plasma, milk, and neutrophils, $1 \mathrm{mg}$ of all-rac $\alpha$-tocopherol would be equivalent to $0.5 \mathrm{mg}$ of $\mathrm{RRR} \alpha$-tocopherol, which is in agreement with the current standards for humans. The minute concentrations of $2 \mathrm{~S}$ isomers found in plasma and milk when all-rac $\alpha$-tocopherol is fed provides additional support for ignoring the $2 \mathrm{~S}$ isomers when calculating $\alpha$-tocopherol equivalents.

\section{CONCLUSIONS}

Based on concentrations of total $\alpha$-tocopherol and tocopherol isomers in plasma, milk, neutrophils, and plasma from calves fed milk, the $2 \mathrm{~S}$ isomers found in all-rac vitamin E has extremely low biological availability in dairy cows. The $2 \mathrm{~S}$ isomers comprise $50 \%$ of the tocopherol found in all-rac; therefore, the $\alpha$-tocopherol equivalence of supplemental RRR vitamin $\mathrm{E}$ is twice that of all-rac vitamin E. Even though feeding an equal amount (IU) of vitamin $\mathrm{E}$ from RRR resulted in greater concentrations of $\alpha$-tocopherol in neutrophils, phagocytosis was greater in neutrophil from cows fed all-rac for unknown reasons.

\section{ACKNOWLEDGMENTS}

Salaries and research support provided by state and federal funds appropriated to the Ohio Agricultural Research and Development Center, The Ohio State University (Paper 19/08AS). Additional support was pro- 
vided by ADM Animal Nutrition and Health (Quincy, IL). Appreciation is expressed to S. K. Jensen, Danish Institute of Agricultural Sciences (Tjele, Denmark) for his assistance in establishing the isomer assay in our laboratory.

\section{REFERENCES}

AOAC. 2000. Official Methods of Analysis. Vol. 1 and 2. 17th ed. AOAC International, Gaithersburg, MD.

Baldi, A., G. Savoini, L. Pinotti, E. Monfardini, F. Cheli, and V. Dell Orto. 2000. Effects of vitamin E and different energy sources on vitamin E status, milk quality and reproduction in transition cows. J. Vet. Med. Ser. A 47:599-608.

Bass, R. T. II, W. S. Swecker, and D. E. Eversole. 2001. Effects of oral vitamin E supplementation during late gestation in beef cattle that calved in late winter and late summer. Am. J. Vet. Res. 62:921-927.

Blatt, D. H., W. A. Pryor, J. E. Mata, and R. Rodriguez-Proteau. 2004. Re-evaluation of the relative potency of synthetic and natural $\alpha$-tocopherol: Experimental and clinical observations. J. Nutr. Biochem. 15:380-395.

Bligh, E. G., and W. J. Dyer. 1959. A rapid method of total lipid extraction and purification. Can. J. Biochem. Physiol. 37:911917.

Cortinas, L., A. Barroeta, J. Galobart, and S. K. Jensen. 2004. Distribution of $\alpha$-tocopherol stereoisomers in liver and thigh of chickens. Br. J. Nutr. 92:295-301.

Drotleff, A. M., and W. Ternes. 2001. Determination of RS,E/Ztocotrienols by HPLC. J. Chromatogr. A 909:215-223.

Eicher, S. D., J. L. Morrill, F. Blecha, C. G. Chitko-McKown, N. V. Anderson, and J. J. Higgins. 1994. Leukocyte functions of young dairy calves fed milk replacers supplemented with vitamins A and E. J. Dairy Sci. 77:1399-1407.

Eicher, S. D., J. L. Morrill, and J. Velazco. 1997. Bioavailability of a-tocopherol fed with retinol and relative bioavailability of $\mathrm{D}-\alpha-$ tocopherol or DL- $\alpha$-tocopherol acetate. J. Dairy Sci. 80:393-399.

Goldner, M., H. Farkas-Himsley, A. Kormendy, and M. Skinner. 1983. Bacterial phagocytosis monitored by fluorescence and extracellular quenching: Ingestion and intracellular killing. Lab. Med. 14:291294.

Gyang, E. O., J. B. Stevens, S. D. Tsitsamis, and E. A. Usenik. 1984. Effects of selenium-vitamin $\mathrm{E}$ injection on bovine polymorphonucleated leukocytes phagocytosis and killing of Staphylococcus aureus. Am. J. Vet. Res. 45:175-177.

Harris, P. L., and M. I. Ludwig. 1949. Relative vitamin E potency of natural and of synthetic $\alpha$-tocopherol. J. Biol. Chem. 179:11111115 .

Herdt, T. H., and J. C. Smith. 1996. Blood-lipid and lactation-stage factors affecting serum vitamin $\mathrm{E}$ concentrations and vitamin $\mathrm{E}$ cholesterol ratios in dairy cows. J. Vet. Diagn. Invest. 8:228232.

Hidiroglou, M., T. R. Batra, and X. Zhao. 1997. Bioavailability of vitamin $\mathrm{E}$ compounds and the effect of supplementation on release of superoxide and hydrogen peroxide by bovine neutrophils. J. Dairy Sci. 80:187-193.

Hogan, J. S., K. L. Smith, W. P. Weiss, D. A. Todhunter, and W. L. Shockey. 1990. Relationships among vitamin E, selenium, and bovine blood neutrophils. J. Dairy Sci. 73:2372-2378.

Hogan, J. S., W. P. Weiss, D. A. Todhunter, K. L. Smith, and P. S. Schoenberg. 1992. Bovine neutrophil responses to parenteral vitamin E. J. Dairy Sci. 75:399-405.

Indyk, H. E. 1988. Simplified saponification procedure for the routine determination of total vitamin $\mathrm{E}$ in dairy products, foods, and tissues by high-performance liquid chromatography. Analyst (Lond.) 113:1217-1221.
IOM (Institute of Medicine). 2000. DRI Dietary Reference Intakes for Vitamin C, Vitamin E, Selenium, and Carotenoids. National Acad. Press, Washington DC.

Jensen, S. K., J. V. Norgaard, and C. Lauridsen. 2006. Bioavailability of $\alpha$-tocopherol stereoisomers in rats depends on dietary doses of all-rac- or RRR- $\alpha$-tocopheryl acetate. Br. J. Nutr. 95:477-487.

Koh, T. S., and T. H. Benson. 1983. Critical re-appraisal of fluormetric method for determination of selenium in biological materials. J. AOAC 66:918-926.

Lauridsen, C., H. Engel, S. K. Jensen, A. M. Craig, and M. G. Traber. 2002. Lactating sows and suckling piglets preferentially incorporate RRR- over all-rac- $\alpha$-tocopherol into milk, plasma and tissues. J. Nutr. 132:1258-1264.

LeBlanc, S. J., T. H. Herdt, W. M. Seymour, T. F. Duffield, and K. E. Leslie. 2004. Peripartum serum vitamin E, retinol, and betacarotene in dairy cattle and their associations with disease. J. Dairy Sci. 87:609-619.

Meglia, G. E., S. K. Jensen, C. Lauridsen, and K. P. Waller. 2006. $\alpha$-Tocopherol concentration and stereoisomer composition in plasma and milk from dairy cows fed natural or synthetic vitamin E around calving. J. Dairy Res. 73:227-234

Ndiweni, N., and J. M. Finch. 1996. Effects of in vitro supplementation with $\alpha$-tocopherol and selenium on bovine neutrophil functions: Implications for resistance to mastitis. Vet. Immunol Immunopathol. 51:67-78.

Nonnecke, B. J., R. L. Horst, W. R. Waters, P. Dubeski, and J. A. Harp. 1999. Modulation of fat-soluble vitamin concentrations and blood mononuclear leukocyte populations in milk replacerfed calves by dietary vitamin A and beta-carotene. J. Dairy Sci. $82: 2632-2641$.

NRC. 2001. Nutrient Requirements of Dairy Cattle. 7th rev. ed. Natl. Acad. Press, Washington, DC.

O'Sullivan, A., K. O'Sullivan, K. Galvin, A. P. Moloney, D. J. Troy, and J. P. Kerry. 2002. Grass silage versus maize silage effects on retail packaged beef quality. J. Anim. Sci. 80:1556-1563.

Politis, I., I. Bizelis, A. Tsiaras, and A. Baldi. 2004. Effect of vitamin E supplementation on neutrophil function, milk composition and plasmin activity in dairy cows in a commercial herd. J. Dairy Res. $71: 273-278$.

Riss, G., A. W. Kormann, E. Glinz, W. Walther, and U. B. Ranalder. 1994. Separation of the eight stereoisomers of all-rac- $\alpha$-tocopherol from tissues and plasma: Chiral phase HPLC and capillary GC. Methods Enzymol. 234:302-310.

SAS Institute. 2004. SAS/STAT User's Guide, Version 9. SAS Institute Inc., Cary, NC.

Smith, K. L., J. S. Hogan, and W. P. Weiss. 1997. Dietary vitamin $\mathrm{E}$ and selenium affect mastitis and milk quality. J. Anim. Sci. 75:1659-1665.

Van Saun, R. J., T. H. Herdt, and H. D. Stowe. 1989. Maternal and fetal vitamin $\mathrm{E}$ concentrations and selenium-vitamin $\mathrm{E}$ interrelationships in dairy cattle. J. Nutr. 119:1156-1164.

Weiss, W. P., J. S. Hogan, and K. L. Smith. 1994. Use of $\alpha$-tocopherol concentrations in blood components to assess vitamin $\mathrm{E}$ status of dairy cows. Agric. Pract. 15:5-8.

Weiss, W. P., J. S. Hogan, K. L. Smith, and K. H. Hoblet. 1990a. Relationships among selenium, vitamin E, and mammary gland health in commercial dairy herds. J. Dairy Sci. 73:381-390.

Weiss, W. P., J. S. Hogan, K. L. Smith, D. A. Todhunter, and S. N. Williams. 1992. Effect of supplementing periparturient cows with vitamin $\mathrm{E}$ on distribution of $\alpha$-tocopherol in blood. J. Dairy Sci. 75:3479-3485.

Weiss, W. P., J. S. Hogan, D. A. Todhunter, and K. L. Smith. 1997. Effect of vitamin E supplementation in diets with a low concentration of selenium on mammary gland health of dairy cows. J. Dairy Sci. 80:1728-1737.

Weiss, W. P., D. A. Todhunter, J. S. Hogan, and K. L. Smith. 1990b. Effect of duration of supplementation of selenium and vitamin E on periparturient dairy cows. J. Dairy Sci. 73:3187-3194. 